\title{
A Dimensão Política da Humanização em Saúde: o Caso da Autonomia do Paciente em Experiências de Práticas (Des)Humanizadas em Saúde Bucal
}

\author{
Carnut, Leonardo; Melo, Ana Mikaele da Silva; Silva, Éven Morgana; Vaz, \\ Fernando Flávio Souza; Carvalho, Samara Juliano; Carvalho, Waleska Oliveira; \\ Júnior, Luiz Gutenberg T. M. C. \\ Universidade de Pernambuco - leonardo.carnut@upe.com
}

\begin{abstract}
Introdução: Sob o princípio da autonomia, pacientes sob tratamentos na área de saúde têm o direito de aceitar ou recusar propostas de tratamento para seus problemas, desde que estejam em pleno gozo de sua capacidade intelectual. o respeito a esse princípio demonstra o cuidado do profissional em tornar a relação de poder menos assimétrica, garantindo ao paciente uma postura mais proativa e, portanto micropoliticamente responsável. Pela característica eminentemente cirúrgica dos procedimentos odontológicos, pode ser que o exercício da autonomia durante a proposição das intervenções seja praticamente inexistente, comprometendo assim, um aspecto importante da dimensão política do cuidado em saúde. Objetivo: Baseado no exposto, o presente estudo objetivou revisar na literatura o relato de experiências nas práticas clínicas em saúde bucal relacionadas à questão ao (des)respeito da autonomia do paciente como base da dimensão política na humanização em saúde. o intuito foi verificar o que a produção científica relata sobre tema, levando-se em consideração os aspectos marcadamente interventivos da assistência odontológica. Método: Tratou-se de uma revisão sistematizada de escopo nacional. Foram utilizadas as bases de dados Medline e SCIELO e selecionados artigos publicados em periódicos nacionais e internacionais. Considerou-se o período compreendido entre 2003 e 2013, teve como limite de idioma o português e espanhol. a estratégia de busca utilizou os descritores: "humanização da assistência", "humanização dos serviços", "autonomia pessoal" e "saúde bucal", após a caracterização dos estudos identificados, foi feita uma análise crítico-reflexiva dos mesmos como foco no exercício da postura autônoma dos pacientes quando submetidos aos tratamentos na área de saúde bucal. Resultados: Totalizouse 77 documentos científicos. Destes foram selecionados 11 e 1 documento do Ministério da Saúde, com base na temática proposta. Detectou-se que há um profundo desconhecimento por parte dos pacientes sobre métodos de tratamento realizados, o que implica em uma não-participação na elaboração dos planos de tratamento, por falta de informação ou incompreensão. o usuário do serviço de saúde precisa perceber que o serviço prestado não é, nem deve ser entendido, como um favor feito à população e sim como um direito adquirido. Conclusões: Sabendo-se que a informação é a base de decisões autônomas, os estudos relatam o severo desrespeito à autonomia dos pacientes, ao passo que, em nenhum estudo revisado foi sequer explorado a explicação das possibilidades terapêuticas. É importante que os pacientes atendidos sejam esclarecidos sobre sua realidade e qual a melhor forma para resolvê-la, devendo, a decisão, respeitar valores e crenças pessoais de cada parte envolvida. uma solução para que a autonomia do paciente seja respeitada pode residir em resgatar funcionários comprometidos e buscar à humanização dos profissionais envolvidos em serviços de saúde pública.
\end{abstract}

Carnut, Leonardo; Melo, Ana Mikaele da Silva; Silva, Éven Morgana; Vaz, Fernando Flávio Souza; Carvalho, Samara Juliano; Carvalho, Waleska Oliveira; Júnior, Luiz Gutenberg T. M. C.. A Dimensão Política da Humanização em Saúde: o Caso da Autonomia do Paciente em Experiências de Práticas (Des)Humanizadas em Saúde Bucal. In: Anais do Congresso Internacional de Humanidades \& Humanização em Saúde [= Blucher Medical Proceedings, num.2, vol.1]. São Paulo: Editora Blucher, 2014. ISSN 2357-7282

DOI 10.5151/medpro-cihhs-10206 